OPEN ACCESS

Edited by: Asad U. Khan,

Aligarh Muslim University, India

Reviewed by:

Georg Gasteiger,

University Medical Center Freiburg,

Germany

Osmar Nascimento Silva Universidade Católica Dom Bosco,

Brazil

*Correspondence:

1-Hsiu Huang

ihsiuhuang@mail.ncku.edu.tw

${ }^{\dagger}$ These authors have contributed equally to this work.

Specialty section: This article was submitted to Antimicrobials, Resistance and Chemotherapy,

a section of the journal Frontiers in Microbiology

Received: 12 April 2017 Accepted: 11 July 2017

Published: 25 July 2017

Citation:

Liu Y-W, Chen Y-H, Chen J-W Tsai P-J and Huang I-H (2017) Immunization with Recombinant TcdB-Encapsulated Nanocomplex Induces Protection against Clostridium difficile Challenge in a Mouse Model.

Front. Microbiol. 8:1411. doi: 10.3389/fmicb.2017.01411

\section{Immunization with Recombinant TcdB-Encapsulated Nanocomplex Induces Protection against Clostridium difficile Challenge in a Mouse Model}

\author{
Yi-Wen Liu't, Yu-Hung Chen't, Jenn-Wei Chen ${ }^{1,3}$, Pei-Jane Tsai, ${ }^{3,4}$ and I-Hsiu Huang ${ }^{1,3 *}$ \\ 1 Department of Microbiology and Immunology, College of Medicine, National Cheng Kung University, Tainan, Taiwan, \\ ${ }^{2}$ Department of Biochemistry and Molecular Biology, College of Medicine, National Cheng Kung University, Tainan, Taiwan, \\ ${ }^{3}$ Center of Infectious Disease and Signaling Research, National Cheng Kung University, Tainan, Taiwan, ${ }^{4}$ Department of \\ Medical Laboratory Science and Biotechnology, College of Medicine, National Cheng Kung University, Tainan, Taiwan
}

Clostridium difficile is considered to be one of the major cause of infectious diarrhea in healthcare systems worldwide. Symptoms of C. difficile infection are caused largely by the production of two cytotoxins: toxin $A(T c d A)$ and toxin $B(T c d B)$. Vaccine development is considered desirable as it would decrease the mounting medical costs and mortality associated with $C$. difficile infections. Biodegradable nanoparticles composed of poly- $\gamma$-glutamic acid $(\gamma$-PGA) and chitosan have proven to be a safe and effective antigen delivery system for many viral vaccines. However, few studies have used this efficient antigen carrier for bacterial vaccine development. In this study, we eliminated the toxin activity domain of toxin $\mathrm{B}$ by constructing a recombinant protein rTcdB consists of residues 1852-2363 of TcdB receptor binding domain. The rTcdB was encapsulated in nanoparticles composed of $\gamma$-PGA and chitosan. Three rounds of intraperitoneal vaccination led to high anti-TcdB antibody responses and afforded mice full protection mice from lethal dose of $C$. difficile spore challenge. Protection was associated with high levels of toxin-neutralizing antibodies, and the rTcdB-encapsulated NPs elicited a longer-lasting antibody titers than antigen with the conventional adjuvant, aluminum hydroxide. Significant reductions in the level of proinflammatory cytokines and chemokines were observed in vaccinated mouse. These results suggested that polymeric nanocomplex-based vaccine design can be useful in developing vaccine against $C$. difficile infections.

Keywords: Clostridium difficile, TcdB, nanocomplex adjuvant, vaccine

\section{INTRODUCTION}

Clostridium difficile is a Gram-positive, anaerobic spore-forming bacterium and is the leading cause of antibiotic-associated diarrhea within hospital settings worldwide (Ananthakrishnan, 2011). It has been estimated that $C$. difficile infections (CDI) are responsible for $15-25 \%$ of all antibioticassociated diarrhea (Bartlett, 2008). Disruptions of the hosts' microbiota by broad-spectrum 
antibiotic treatments, such as clindamycin, or alteration in the endogenous gastrointestinal flora are considered major risk factors for C. difficile infection (Bartlett, 2008; Ananthakrishnan, 2011). CDI can result in a wide spectrum of signs ranging from asymptomatic colonization, mild to severe chronic diarrhea, pseudomembranous colitis, and even death due to multiple organ failures (Dobson et al., 2003; Aslam and Musher, 2006). Treatment of CDI mainly relies on the use of metronidazole and vancomycin, although increasing cases of treatment failure or multiple relapses have raised concern over the need for alternative treatments (Ananthakrishnan, 2011). Furthermore, since treatment still relies on antibiotic usage, the normal flora is not easily restored. In addition, $C$. difficile spores can be present in the hospital setting, thus multiple relapses are quite common and making effective treatment difficult (Johnson, 2009). In recent years alternative therapeutic approaches such as fecal material transplantation (FMT) have gained ground as being effective and patients experience fewer relapses due to the recolonization of the intestinal microbiota (Borgia et al., 2015). However, safety issues can still exist with FMT due to the lack of knowledge of the effective component within the fecal sample (Borgia et al., 2015). Therefore, a vaccine approach is highly desired.

Clostridium difficile infections is a toxin-mediated intestinal disease. Biochemical and molecular studies have shown that the major virulence factors of toxigenic $C$. difficile are the large secreted glucosyltransferase protein toxins TcdA and TcdB, which are encoded within the PaLoc locus (Braun et al., 1996; Awad et al., 2014). Collectively the toxins act on the intestinal epithelium of the host and stimulate intestinal fluid secretion and proinflammatory responses that lead to diarrhea and colitis. The respective roles of $\mathrm{TcdA}$ and $\mathrm{TcdB}$ have been extensively studied. Carter et al. (2012) demonstrated that TcdB is the major virulence factor and $\mathrm{TcdB}$ alone was sufficient to induce severe organ damages in vivo (Carter et al., 2015). However, other studies using mutants have shown that strains expressing only TcdA retained virulence (Kuehne et al., 2010). Clinically, while naturally occurring TcdA - TcdB + strains have been isolated frequently from patients, few cases have been reported of naturally occurring TcdA $+\mathrm{TcdB}$ - strains in literature (Johnson et al., 2003; Monot et al., 2015). Nevertheless, both TcdA and $\mathrm{TcdB}$ are immunogenic and have been used as candidate antigens for the majority of vaccine studies to date (Zhao S. et al., 2014; Kociolek and Gerding, 2016).

Both TcdA and TcdB share similar C-terminal receptor binding domains (RBDs) that mediate the binding of toxins to carbohydrate receptors on the surface of host cells (Di Bella et al., 2016). Past immunization studies using the RBDs of $C$. difficile toxins have been shown to induce antibody responses with toxinneutralizing activity in mice or hamsters challenged with either toxins or live bacteria (Baliban et al., 2014; Maynard-Smith et al., 2014; Guo et al., 2015; Huang et al., 2015; Wang et al., 2015; Bezay et al., 2016).

A critical component of any vaccine is the adjuvant. Adjuvants are essential for enhancing and directing the adaptive immune response to vaccine antigens (Leroux-Roels, 2010). The most common and traditional adjuvant for human vaccines is aluminum salt (Alum) which has been in use for about 90 years
(Glenny, 1930). Other non-mineral salt based adjuvants such as lipid particles, microparticles, immune potentiators and natural polymers have also been extensively tested in pre-clinical or clinical trials (Reddy et al., 2007; Leroux-Roels, 2010; Karch and Burkhard, 2016; Kalam et al., 2017). Among these adjuvants, natural polymer based nanoparticles, which has been used ad drug delivery systems, have also shown to be a safe and effective vaccine adjuvant (Mishra et al., 2010; Moon et al., 2012; Zhao K. et al., 2014). However, the effectiveness of using nanoparticles as C. difficile vaccine adjuvant have not been studied in the past. In this study, we evaluated a nanoparticle vaccine consisted of recombinant TcdB RBD encapsulated by a mixture of chitosan and poly- $\gamma$-glutamic acid ( $\gamma$-PGS) for the ability to induce neutralizing antibodies and to protect mice from lethal $C$. difficile spore challenge.

\section{MATERIALS AND METHODS}

\section{Clostridium difficile and Escherichia coli Culturing Conditions}

Clostridium difficile strains were cultured anaerobically on brain-heart infusion (BHI) agar or in BHI broth (Thermo Scientific, Waltham, MA, United States) supplemented with $0.05 \%$ L-cysteine. Anaerobic experiments were conducted inside a Don Whitley DG250 anaerobic workstation (Don Whitley Scientific Ltd, West Yorkshire, United Kingdom). E. coli strains were grown at $37^{\circ} \mathrm{C}$ in LB (Luria Broth, Thermo Scientific, Waltham, MA, United States).

\section{Spore Preparations}

Spores were prepared by plating a 1:100 dilution of overnight culture onto BHIS agar plates and then incubated for 10 days at $37^{\circ} \mathrm{C}$ under anaerobic conditions. Spores were harvested with ice-cold sterile distilled water and purified with 50\% Nicodenz (Axis Shield, Oslo, Norway) as previously described (Sorg and Sonenshein, 2008). Spores were purified to $>99 \%$ purity as determined by phase contrast microscopy and the number of spores/ $\mathrm{ml}$ was quantified by visual enumeration using a Neubauer Chamber (Sigma-Aldrich, St. Louis, MO, United States). Spores were stored at $-80^{\circ} \mathrm{C}$ and viability were confirmed by plating onto $\mathrm{BHI}$ agar containing the germinant sodium taurocholate prior to use.

\section{Protein Overexpression and Purification}

Recombinant TcdB antigen was constructed based on part of the TcdB RBD (amino acids 1852-2363). Genomic DNA of C. difficile strain R20291 was used in a PCR reaction with primers tcdB-F and tcdB-R (Table 1). Restriction endonuclease sites (EcoRI at the $3^{\prime}$-end and HindIII at the $5^{\prime}$-end) were designed into the primers. The PCR-amplified product was subsequently cloned into the pET21B expression vector (Merck Millipore, Darmstadt, Germany) and transformed into E. coli BL21 (DE3). The sequence of the recombinant plasmid was confirmed by a commercial sequencing company (Genomics, Taiwan). Expression of recombinant $6 x$ His-tagged $\mathrm{TcdB}$ protein was 
TABLE 1 | Sequences of oligonucleotide primers used in this study.

\begin{tabular}{|c|c|c|c|}
\hline Name & Sequence $\left(5^{\prime}\right.$ to $\left.3^{\prime}\right)$ & Species & Reference \\
\hline $\mathrm{mlL}-1 \beta-\mathrm{F}$ & GCA ACT GTT CCT GAA CTC AAC T & Mouse & Hung et al., 2015 \\
\hline $\mathrm{mlL}-1 \beta-\mathrm{R}$ & ATC TाT TGG GGT CCG TCA AT & Mouse & Hung et al., 2015 \\
\hline mIL-17A-F & GCT CCA GAA GGC CCT CAG A & Mouse & Hung et al., 2015 \\
\hline mlL-17A-R & CTT TCC CTC CGC ATT GAC A & Mouse & Hung et al., 2015 \\
\hline mlL-6-F & AGG ATA CCA CTC CCA ACA GAC & Mouse & Hung et al., 2015 \\
\hline mlL-6-R & GTG CAT CAT CGT TGT TCA TAC & Mouse & Hung et al., 2015 \\
\hline $\mathrm{mTNF} \alpha-\mathrm{F}$ & CAT CTT CTC AAA ATT CGA GTG ACA A & Mouse & Hung et al., 2015 \\
\hline $\mathrm{mTNF} \alpha-\mathrm{R}$ & TGG GAG TAG ACA AGG TAC AAC CC & Mouse & Hung et al., 2015 \\
\hline mMIP-2-F & TGT CAA TGC CTG AAG ACC CTG CC & Mouse & Hung et al., 2015 \\
\hline mMIP-2-R & AAC $\Pi \pi$ गT ACC GCC CTा GAG AGT GG & Mouse & Hung et al., 2015 \\
\hline mIFN-r-F & GCC ATC AGC AAC AAC ATA AGC GTC & Mouse & Hung et al., 2015 \\
\hline mIFN-r-R & CCA CTC GGA TGA GCT CAT TGA ATG & Mouse & Hung et al., 2015 \\
\hline mMCP-1-F & CCС ACT CAC CTG CTG CTA CT & Mouse & Hung et al., 2015 \\
\hline 0 & TCT GGA CCC ATT CCT TCT TG & Mouse & Hung et al., 2015 \\
\hline $\operatorname{slpA}(E c o R I)-F$ & TAC GAATTCG GCA GAA GAT ATG TCG AAA GTT GAG & C. difficile & This work \\
\hline slpA (HindllI)-R & ACC AAGCTT ACT CTT AGT TGT AAC TCT ПTा TCC & C. difficile & This work \\
\hline tcdB (EcoRl)-F & TAC GAATTCG TTG ATA ACT GGA TTT ACA ACT & C. difficile & This work \\
\hline tcdB (HindllI)-R & ACC AAGCTT CAC TAA TTG AGC TGT ATC AGG & C. difficile & This work \\
\hline
\end{tabular}

induced by adding $0.5 \mathrm{mM}$ isopropyl- $\beta$-D-thiogalactopyranoside (IPTG) when the cells reached an O.D.600 of 0.6, and further incubated at $37^{\circ} \mathrm{C}$ for $4 \mathrm{~h}$. Cells were centrifuged at $8000 \mathrm{rpm}$ for $30 \mathrm{~min}$ at $4^{\circ} \mathrm{C}$, resuspended in phosphate buffer saline (PBS; $137 \mathrm{mM} \mathrm{NaCl}, 2.7 \mathrm{mM} \mathrm{KCl}, 10 \mathrm{mM} \mathrm{Na} 2 \mathrm{HPO} 4$, $2 \mathrm{mM} \mathrm{KH} 2 \mathrm{PO} 4, \mathrm{pH}$ 6.5), and disrupted by sonication on ice. Next, the supernatants were loaded into an Ni-NTA column (GE Healthcare Life Sciences, Pittsburg, PA, United States) and contaminant proteins were eliminated through a washing procedure by using $50 \mathrm{mM}$ imidazole in wash buffer (20 mM NaH2PO4, $500 \mathrm{mM} \mathrm{NaCl}, 50 \mathrm{mM}$ imidazole, $\mathrm{pH}$ 6.5). Proteins were eluted with $500 \mathrm{mM}$ imidazole in wash buffer. After SDS-PAGE analysis, proteins were concentrated by Amicon $^{\circledR}$ Ultra 30-kDa cut-off unit (Merck Darmstadt, Germany). The $6 x$ His-tag of $\mathrm{rTcdB}$ was removed by the Thrombin CleanCleave ${ }^{\mathrm{TM}}$ kit (GE Healthcare Life Sciences, Pittsburg, PA, United States) according to the manufacturer's instructions. Tag-less recombinant proteins were verified by Western blots. All recombinant proteins were subsequently stored at $4^{\circ} \mathrm{C}$ for future use.

\section{Preparation and Characterization of Empty and Antigen Containing Nanoparticles}

The antigen loaded chitosan $/ \gamma$-PGA NPs were prepared by flush mixing of an aqueous $\gamma$-PGA ( $1 \mathrm{ml}$, unfractionated $\gamma$-PGA) into an aqueous chitosan ( $\mathrm{pH} 6.0,5 \mathrm{ml})$ at various weight ratios under magnetic stirring at room temperature (Lin and Chen, 2017). The obtained nanoparticle solution was then dialyzed (MWCO: 10000, Spectrum Labs, Rancho Dominguez, CA, United States) against deionized water for 3 days. The stock solutions of chitosan and $\gamma$-PGA were prepared by mixing $\gamma$-PGA with chitosan solution. After vacuum drying, nanoparticles were homogenized with phosphate-buffered saline (PBS, $\mathrm{pH}$ 7.0). The particle size, polydispersity index (PDI) and zeta potential of the prepared nanoparticles were measured using a Zetasizer (3000HS, Malvern Instruments, Malvern, United Kingdom). For the preparation and characterization of polymer-based nanoparticle encapsulated rTcdB, rTcdB protein was premixed with aqueous $\gamma$-PGA and added into aqueous chitosan under magnetic stirring in $10 \mathrm{mM}$ phosphate buffer $(\mathrm{pH} \mathrm{6.0)}$ at room temperature. The samples were concentrated to $1 / 10$ of volume and stored at $4^{\circ} \mathrm{C}$. The particle size and zeta potential of the prepared nanoparticles were measured using a quasi-elastic light scattering (QELS) analyzer (3000HS, Malvern Instruments, Malvern, United Kingdom).

\section{Mice Immunization and Sample Collection}

Specific-pathogen-free 6-weeks old male C57BL/6 mice were housed in the Laboratory Animal Center of National Cheng Kung University. All mice were maintained and handled according to the guidelines of the Institutional Animal Care and Use Committee (IACUC) of National Cheng Kung University (NCKU). All animal studies were performed following a protocol approved by the IACUC of NCKU (approval NCKU-IACUC102-149). Mice were vaccinated intraperitoneally every other week for a total of three injections. For optimization of nanoparticle sizes, eight groups of three mice each were injected intraperitoneally with the following inoculant: (1) sterile PBS control; (2) NPs only (200 nm); (3) purified rTcdB; (4) $\mathrm{NP}_{200}$; (5) $\mathrm{NP}_{350}$; (6) $\mathrm{NP}_{500}$; (7) $\mathrm{NP}_{750}$; (8) $100 \mu \mathrm{g}$ of rTcdB in PBS mixed with aluminum hydroxide $[\mathrm{Al}(\mathrm{OH}) 3 ; 1: 1$ by volume] (Thermo). For C. difficile challenge experiments, mice in groups of 5 were vaccinated with the following: (1) sterile PBS control; (2) empty NPs only; and (3) $\mathrm{NP}_{750}$. A total of $20 \mu \mathrm{g}$ of $\mathrm{rTcdB}$ were administered to each mouse per injection. All injections were performed intraperitoneally. Serum samples were collected 
from each animal via submandibular collection 1 week after each vaccination and stored at $-80^{\circ} \mathrm{C}$ prior to use.

\section{Detection of Vaccine-Induced Specific IgG and IgA by ELISA}

TcdB-specific IgA and IgA were determined by enzyme-linked immunosorbent assay (ELISA). Purified rTcdB proteins were coated onto ELISA plates (Nunc, Roskilde, Denmark) using coating buffer (20 mM NaCO3, $35 \mathrm{mM} \mathrm{NaHCO} 3, \mathrm{pH} 9.6)$ at $4^{\circ} \mathrm{C}$ overnight. The wells were then blocked with $10 \%$ skim milk in PBS ( $\mathrm{pH} \mathrm{7.4)}$ at room temperature. To detect the antigenspecific antibody, mouse serum samples were diluted in PBS and incubated for $1 \mathrm{~h}$ at $37^{\circ} \mathrm{C}$. Plates were washed 3 times with $0.05 \%$ Tween 20 in PBS (PBS/T) and then incubated with HRP-conjugated anti-mouse IgG or IgA for $1 \mathrm{~h}$ at $37^{\circ} \mathrm{C}$. Colors were developed by tetramethylbenzidine substrate (TMB) and the reaction stopped by adding stop solution $\left(2 \mathrm{M} \mathrm{H}_{2} \mathrm{SO}_{4}\right)$. Absorbance was measured at $450 \mathrm{~nm}$ using iMark ${ }^{\mathrm{TM}}$ Microplate Reader (Bio-Rad, Hercules, CA, United States).

\section{Cell Culture}

Vero cells were cultured in Dulbecco's modified Eagles medium (DMEM) containing Penicillin-Streptomycin and $10 \%$ fetal bovine serum (FBS) in a humidified incubator containing 5\% $\mathrm{CO}_{2}$ at $37^{\circ} \mathrm{C}$. Cells were detached using $1000 \mathrm{U} / \mathrm{ml}$ trypsin and $0.5 \mathrm{mM}$ EDTA and counted by LUNA-FL ${ }^{\mathrm{TM}}$ Dual Fluorescence Cell Counter (Logos Biosystems, Anyang, South Korea). Then cells were seeded into a 96 well tissue culture test plate (SPL life sciences, Pocheon, South Korea) at a density of $5 \times 10^{4}$ cells per well and incubated at $37^{\circ} \mathrm{C}$ containing $5 \% \mathrm{CO}_{2}$ overnight.

\section{Neutralizing Antibody Assay}

Toxin neutralizing properties of antiserum were determined using Vero cells and C. difficile purified toxin B (List Biological Labs, Campbell, CA, United States). Serum samples obtained from all immunized mice were serially diluted in DMEM and incubated for $1 \mathrm{~h}$ at $37^{\circ} \mathrm{C}$ with toxin $\mathrm{B}$ (final concentration $0.5 \mathrm{ng} / \mathrm{ml}$ ). The toxin-serum mixtures were then added to 96 well plates containing Vero cells and the plates were incubated at $37^{\circ} \mathrm{C}$ containing $5 \% \mathrm{CO} 2$ for $18 \mathrm{~h}$. After incubation, the culture supernatant was collected and incubated with the substrate mixture from the Cytotoxicity detection kit (Roche, Basel, Switzerland) for $30 \mathrm{~min}$ in dark. The lactate dehydrogenase $(\mathrm{LDH})$ activity was then determined at $492 \mathrm{~nm}$ using iMark $^{\mathrm{TM}}$ Microplate Reader (Bio-Rad, Hercules, CA, United States), and cytotoxicity was calculated from the following equation. Statistical analyses were performed using GraphPad Prism version 6.0.

Cytotoxicity $(\%)=$

(exp.value - background) - (low control - background) $\overline{(\text { high control - background })-(\text { low control - background })} \times 100 \%$

Background control $=$ medium only + reagent only Low control $=$ spontaneous $\mathrm{LDH}$ release
High control $=$ maximum $\mathrm{LDH}$ release

\section{Animal Model of CDI}

After pre-vaccination, mice were fed drinking water containing an antibiotic mixture, which included $0.4 \mathrm{mg} / \mathrm{ml}$ vancomycin, $0.215 \mathrm{mg} / \mathrm{ml}$ metronidazole, $0.4 \mathrm{mg} / \mathrm{ml}$ kanamycin, $0.035 \mathrm{mg} / \mathrm{mL}$ gentamycin, and $850 \mathrm{U} / \mathrm{ml}$ colistin, for a total of 5 days before challenge. All antibiotics were purchased from Sigma-Aldrich. Vancomycin and metronidazole were omitted to avoid disrupting C. difficile colonization on the day before challenge. $1 \times 10^{6} \mathrm{CFU}$ of C. difficile R20291 spores were administered orogastrically and $4 \mathrm{mg} / \mathrm{kg}$ of clindamycin was injected intraperitoneally. 2 days post infection, all animals were sacrificed. Serum and organs were extracted for downstream analysis. Serum samples were stored at $-80^{\circ} \mathrm{C}$ prior to use. For survival rate analysis, following oral challenge, mice were monitored daily for a total of 5 days for diarrhea and other signs of disease, and moribund animals were euthanized.

\section{Cytokine and Chemokine Measurement}

The concentrations of gastrointestinal lavage (GAL) cytokines and chemokines were measured by DuoSet ${ }^{\circledR}$ ELISA Development system (R\&D Systems, Minneapolis, MN, United States) according to the manufacturer's instruction. Absorbance was measured at $450 \mathrm{~nm}$ using iMark ${ }^{\mathrm{TM}}$ Microplate Reader (Bio-Rad, Hercules, CA, United States). Samples were measured in triplicate and statistical analyses were performed using GraphPad Prism version 6.0 .

\section{Fecal Colony Forming Unit Determination}

Fecal samples (premixed in PBS) were collected from animals and immediately subjected to heat treatment at $65^{\circ} \mathrm{C}$ for $20 \mathrm{~min}$ and then serially diluted onto $\mathrm{BHI}$ agar containing $0.1 \%$ taurocholate. Plates were incubated anaerobically at $37^{\circ} \mathrm{C}$ for $48 \mathrm{~h}$ and colonies were counted for CFU determination.

\section{RNA Extraction and Real-Time Quantitative Reverse Transcription PCR (qRT-PCR)}

The colon samples were extracted with RNeasy ${ }^{\circledR}$ Plus Mini kit (QIAGEN, Venlo, Netherlands). RNA yield and quality were checked by NanoDrop Spectrophotometer (Thermo Scientific, Waltham, MA, United States). Reverse transcription was performed with SuperScript ${ }^{\mathrm{TM}}$ II Reverse Transcriptase (Invitrogen, Waltham, MA, United States). The expression level of proinflammatory cytokines and chemokines were measured by quantitative reverse transcription-polymerase chain reaction using RealQ Plus 2X Master Mix Green (Ampliqon, Denmark) with $\beta$-actin as the reference gene in each reaction (Table 1 ). The data were analyzed by using the $\Delta \Delta \mathrm{Ct}$ method and expressed as the fold change in transcript level under the test condition compared to the average for the indicated control and then normalized to the reference gene $\beta$-actin. Statistical analyses were done by using GraphPad Prism 6.0. 


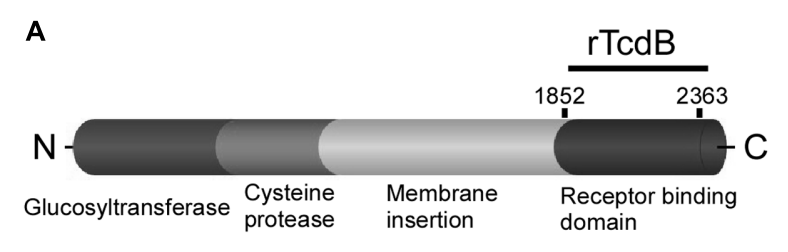

B

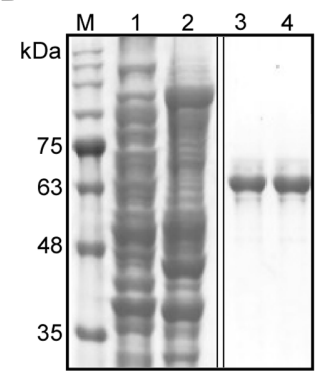

C

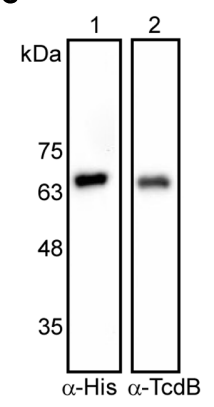

D

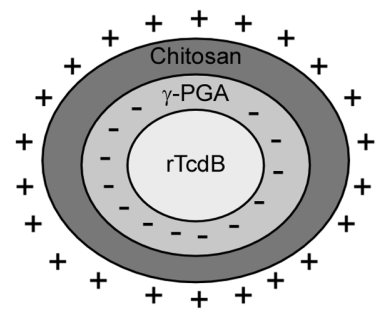

FIGURE 1 | Purification of recombinant TcdB and the composition of NP-rTcdBs. (A) Functional domains of TcdB and regions included for nanoparticle vaccine construction. (B) Coomassie blue staining of purified rTcdB. rTcdB were purified from $E$. coli by His-tag affinity chromatography. Lanes 1 and 2: Total $E$. coli lysates containing $r T c d B$ and unbound proteins. Lanes 3 and 4: Purified rTcdB with. (C) Immunoblotting confirmation of rTcdB. M. Protein markers. rTcdB from SDS-PAGE was transferred to a membrane and detected by anti-His (lane 1) and anti-TcdB (lane 2). (D) Composition of NP-rTcdBs. The ionized chitosan and $\gamma$-PGA were able to form polyelectrolyte complexes via electrostatic interactions, resulting in a matrix structure with a spherical shape.

\section{Statistics}

All data were expressed as the mean \pm standard deviations and statistical comparisons among the groups were analyzed by Student's $t$-test. Multiple intergroup comparisons were assessed by one-way ANOVA, followed by post hoc Tukey's test with GraphPad Prism version 6.0. Statistical significance was set at $P<0.05$.

\section{RESULTS}

\section{Preparation of Recombinant rTcdB and Nanoparticle Vaccine}

As the immunogenicity of TcdB has been well studied, in order to evaluate the potential of using nanoparticles as $C$. difficile vaccine adjuvants, our vaccine design started with the expression of recombinant $C$. difficile toxin $\mathrm{B} \mathrm{RBD}$. The $\mathrm{RBD}$ of $\mathrm{TcdB}$ is nontoxic, have been used in other vaccine studies in the past, and is relatively easy to express and purify when compared to the full length toxin (Wang et al., 2012; Baliban et al., 2014; Spencer et al., 2014; Huang et al., 2015). The fragment comprised only the C-terminal domain region (rTcdB, amino acids 1852-2363) to avoid cytotoxicity (Figure 1A). PCR products were cloned into pET-21b and then transformed into E. coli. rTcdB was expressed in $E$. coli and purified from soluble extracts by Ni2+-NTA affinity chromatography (Figure 1B). Proteins were further purified to homogeneity by size-exclusion chromatography. The identity of the recombinant proteins were confirmed by Western blot analysis using Anti-His and Anti-TcdB antibody (Figure 1C). The overall purification yield from E. coli extracts was $4.5-5.0 \mathrm{mg} / \mathrm{L}$ of E. coli culture. His-tag of purified $\mathrm{rTcdB}$ was removed by thrombin cleavage.

Nanoparticles were produced using an electro-kinetic approach involving the ionic attraction of chitosan (containing positively charged $-\mathrm{NH} 3$ group) and $\gamma$-PGA (containing negatively charged -C00- group) which are both FDAapproved biodegradable polymers. Specific procedures for the encapsulation of $\mathrm{rTcdB}$ are described in the Section "Materials and Methods." As the size of nanoparticles might influence the immunogenicity of the vaccine, we generated four different rTcdB-encapsulated nanoparticles (NP-rTcdB) with the designation $\mathrm{NP}_{200}, \mathrm{NP}_{350}, \mathrm{NP}_{500}$, and $\mathrm{NP}_{750}$ with each type of particles having a mean particle diameter of 200, 350, 500, and $750 \mathrm{~nm}$, respectively. All NPs, regardless of size, contained same amount of antigen.

\section{Immunogenicity of Different Sizes of Nanoparticle Vaccine}

To evaluate the immunogenicity of rTcdB-encapsulated nanoparticles, mice were vaccinated three times intraperitoneally with prepared nanoparticle vaccines. Sera were collected from mice before primary immunization and 1 week after each booster. No significant rTcdB specific IgGs were detected in mice injected with empty nanoparticles as expected, while IgGs were not detected in mice injected with purified recombinant rTcdB until 1 week after the third immunization (Figure 2). In contrast, significant IgGs were detected as earlier as 1 week after the second immunization for all NP-rTcdB immunized mice compared to the control groups (Figure 2). Immunization with Alum-mixed rTcdB induced detectable IgG responses albeit at a significantly lower level compared to NP-rTcdB injected groups. In terms of differences in nanoparticle sizes, while mice vaccinated with $\mathrm{NP}_{200}$ appeared to have higher IgGs after the first injection, $\mathrm{NP}_{500}$ and $\mathrm{NP}_{750}$ elicited a higher level of IgG with subsequent boosters. The highest IgG level detected for all sizes of nanoparticles were after the third immunization.

On the other hand, rTcdB-specific IgAs were observed only after the third immunization (Figure 3). All four sizes of nanoparticle vaccines induced a detectable level of IgAs with a general trend toward larger NPs inducing higher antibody responses. Only baseline titers were observed in empty NPs 


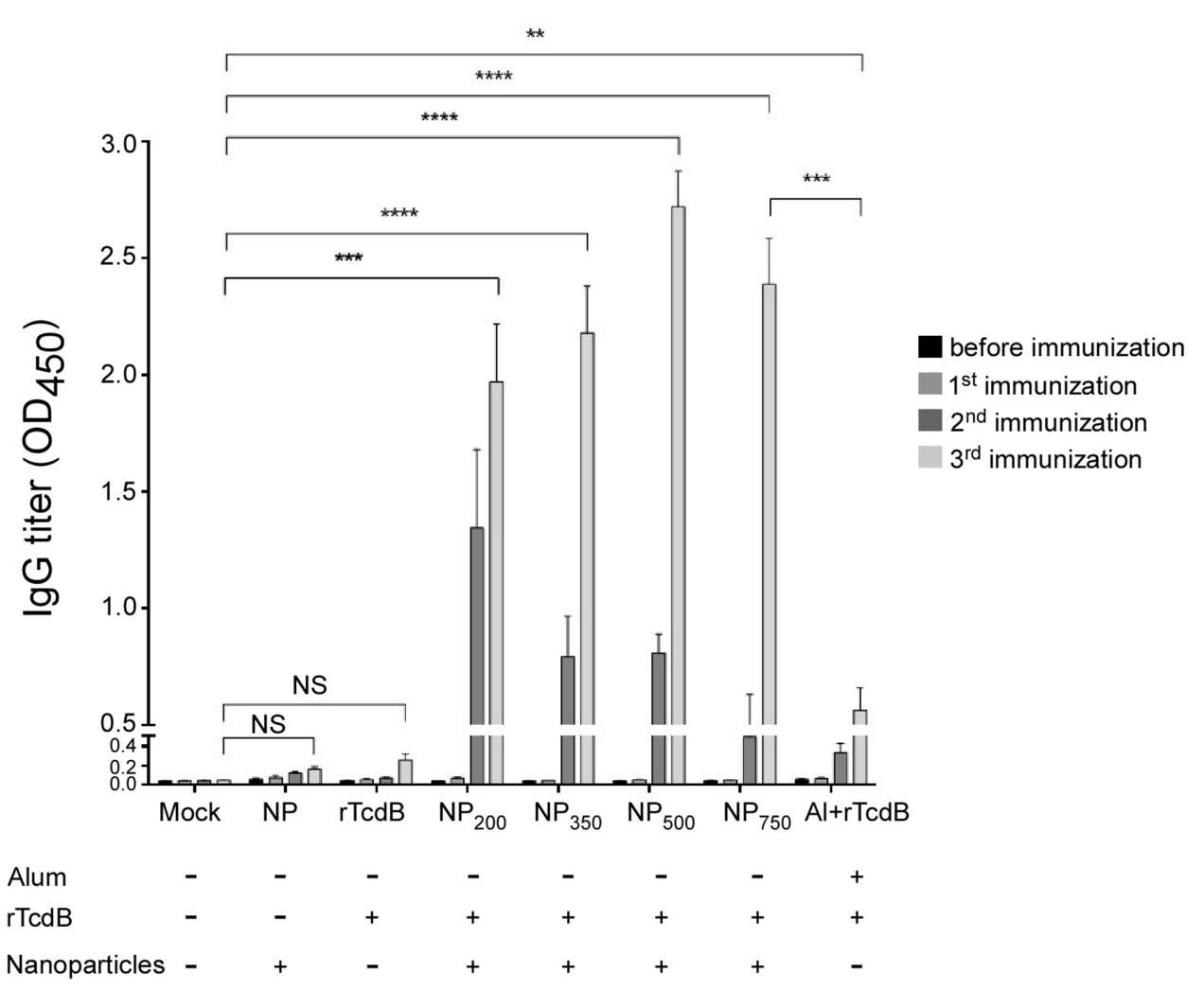

FIGURE 2 | Induction of antigen-specific IgG in nanoparticle vaccinated mice. ELISA was performed in triplicate using coated peptide pool. Serum IgGs (1:20,000 dilution) in differentially immunized mice were compared. Mock: PBS injection only; NP: empty nanoparticle infection; rTcdB: injection with $20 \mu \mathrm{g}$ purified rTcdB in PBS. $\mathrm{NP}_{200}, \mathrm{NP}_{350}, \mathrm{NP}_{500}$, and $\mathrm{NP}_{750}$ : injection with NP-rTcdBs with the corresponding size in nanometers; $\mathrm{Al}+\mathrm{rTcdB}$ : injection with $20 \mu \mathrm{g}$ purified rTcdB mixed with Alum. All data are presented as mean \pm standard deviations and statistical comparisons among groups were analyzed by Student's $t$-test and ANOVA $\left(* * p \leq 0.01,{ }^{* * *} p \leq 0.001,{ }^{* * * *} p \leq 0.0001\right)$. NS, not significant. All data are representative of at least three independent experiments.

immunized control, purified rTcdB immunized control, and the PBS control groups. Alum-mixed rTcdB induced little to no IgAs. Taken together, these results showed that vaccination with NP-rTcdB was much more effective in inducing antigen-specific IgG and IgA than the traditional aluminum hydroxide adjuvant.

To determine the functional capacity of anti-rTcdB antibodies induced by our nanoparticle vaccine to neutralize native toxin $\mathrm{B}$, neutralizing efficacy was assessed against purified toxin B (Figure 4). After incubation of Vero cells with serial dilutions of serum, the cells were assayed for the release of lactate dehydrogenase (LDH). Antibodies raised against nanoparticle vaccines were found to have neutralizing activity in a dosedependent manner and no significant differences were observed between all four NP sizes (Figure 4). Control animals that received adjuvant alone or $\mathrm{rTcdB}$ alone did not produce sufficient antibodies to neutralize the cytotoxic effect of toxin B (data not shown).

\section{Persistence of the Nanoparticle Vaccine-Induced Antibodies}

To further evaluate the potency of various sizes of NP-rTcdB as vaccine candidates, serum antibody responses of immunized mice were measured for up to 6 months after the last immunization. As shown in Figures $\mathbf{5 A}, \mathbf{B}$, both $\operatorname{IgG}$ and $\operatorname{IgA}$ levels detected in all NP-rTcdB vaccinated mice peaked after the third immunization and were still detectable 6 months after the last immunization (Figure 5). Antibody titer for $\mathrm{NP}_{750}$ vaccinated mice at 6-month after immunization were either not significantly different (IgGs) or higher (IgAs) than those that were immunized with alum mixed $\operatorname{rTcdB}(P<0.05)$. In terms of nanoparticle size, IgG titer of $\mathrm{NP}_{750}$ immunized mice at 6-month post-immunization were significantly higher than mice immunized with smaller size nanoparticle vaccines $(P<0.05)$.

\section{Protective Efficacy of Nanoparticle Vaccine}

In order to determine the protective efficacy of immunization with nanoparticle vaccines upon challenge with $C$. difficile spores. The high-toxin producing C. difficile strain R20291 was used for infection. We immunized C57BL/6 mice by i.p. injection with $\mathrm{NP}_{750}$ three times. Control groups include mice immunized with PBS alone, and empty nanoparticle alone. After the third immunization, the normal gut microbiota of immunized mice was perturbed with antibiotic cocktails dissolved in the drinking water for 5 days followed by a single i.p. injection of 


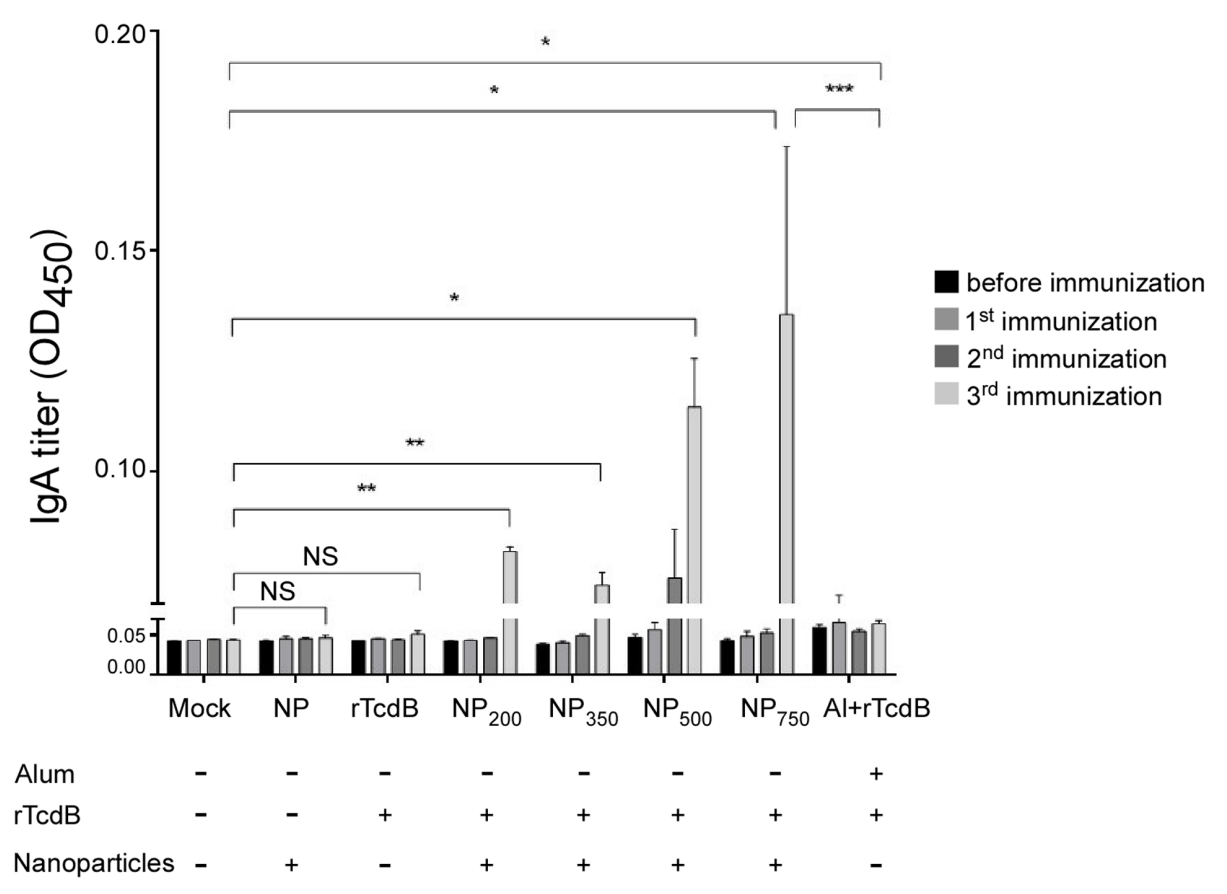

FIGURE 3 | Induction of antigen-specific IgA in nanoparticle vaccinated mice. ELISA was performed in triplicate using coated peptide pool. Serum IgAs (1:1,000 dilution) in differentially immunized mice were compared ( $n=5$ per group). Mock: PBS injection only; NP: empty nanoparticle infection; $r T c d B$ : injection with $20 \mu g$ purified rTcdB in PBS. NP $200, \mathrm{NP}_{350}, \mathrm{NP}_{500}$, and $\mathrm{NP}_{750}$ : injection with NP-rTcdBs with the corresponding size in nanometers; Al+rTcdB: injection with $20 \mu \mathrm{g}$ purified rTcdB mixed with Alum. All data are presented as mean \pm standard deviations and statistical comparisons among groups were analyzed by Student's $t$-test and ANOVA $\left(n=5,{ }^{*} p \leq 0.05,{ }^{*} p \leq 0.01,{ }^{* * *} p \leq 0.001\right)$. NS, not significant. All data are representative of at least three independent experiments.

clindamycin prior to challenge with purified R20291 C. difficile spores $\left(5 \times 10^{5}\right.$ spores $)$. Infected mice in the control group receiving either PBS or empty nanoparticle (NP) showed signs of CDI, including loss of body and cecal weight and a decrease in colon length (Figures 6A-C). Gross view of colon and cecum indicated acute stage of colitis (Figure 6D). In contrast, $\mathrm{NP}_{750}$ immunized animal displayed no body weight loss and cecum weight and colon length were similar to that of the healthy control (Vehicle). Gross view of colon and cecum from $\mathrm{NP}_{750}$ vaccinated mice also were similar in appearance to the healthy control with visibly formed fecal samples being retained in the colon (Figure 6D). Serum samples obtained before and post-infection were obtained and evaluated by ELISA to assess the development of specific antibody response. Serum from $\mathrm{NP}_{750}$ immunized group induced significant serum IgG and IgA responses post infection, while only baseline titers were detected from the PBS and NP control group (Figures 7A,B). In addition to systemic antibody response, the GAL were collected from each mouse to test for intestinal antigen-specific antibody responses. As shown in Figure 7C, significantly higher IgG responses were detected from GAL samples of $\mathrm{NP}_{750}$ immunized mice compared to control groups. As expected, no detectable IgAs were observed in samples from NP100 group since the vaccine was delivered intraperitoneally. To assess whether immunization with NP-rTcdBs would also influence $C$. difficile replication, fecal samples were collected from animals 2 days post infection. As shown in Supplementary
Figure 1, no significant differences were observed between all groups.

Consistent with the results observed above, the expression of proinflammatory cytokines interleukin 6 (IL-6), interleukin $1 \beta$ (IL-1 $\beta$ ), tumor necrosis factor $\alpha$ (TNF- $\alpha)$, interferon $\gamma$ (IFN- $\gamma)$, macrophage inflammatory protein 2 (MIP-2), monocyte chemoattractant protein 1 (MCP-1), and interleukin 17A (IL-17A), was significantly increased in colons of the control group mice vaccinated with PBS or empty nanoparticle compared to healthy control (Figure 8A). In contrast, colons from the $\mathrm{NP}_{750}$ immunized group contained significantly lower level of inflammatory cytokines and chemokines level with the exception of IL-17A (Figure 8A). In addition, proinflammatory cytokines and chemokines within GAL were measured by ELISA (Figure 8B). The level of IL-6, IL-1 $\beta$, TNF- $\alpha$, and MCP-1 was increased in GAL of mice immunized with PBS or empty nanoparticles compared to the healthy control. However, mice immunized with $\mathrm{NP}_{750}$ displayed significant decrease level of cytokines and chemokines tested (Figure 8B).

Finally, the survival rate of i.p. immunized animal post infection was recorded for up to 6 days post-infection (Figure 9). Eighty of mice in control groups vaccinated with PBS or empty nanoparticle were susceptible to $C$. difficile infection and died on day 3 post infection. In contrast, all mice vaccinated with $\mathrm{NP}_{750}$ were completely protected against the lethal C. difficile 


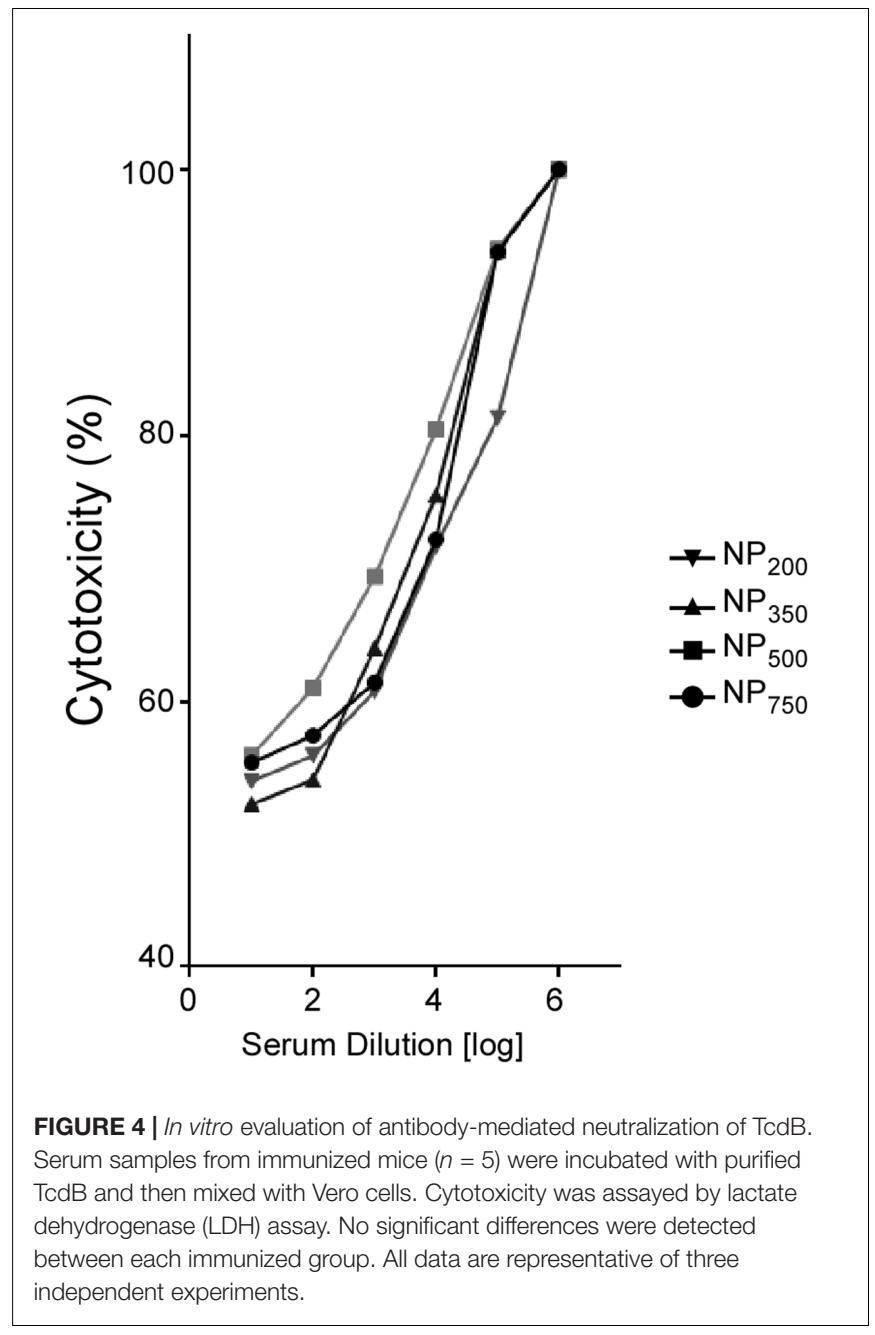

spore challenge $(P<0.001)$. In short, these results suggest that immunization with nanoparticle vaccines can protect mice from severe CDI.

\section{DISCUSSION}

Clostridium difficile is one of the major cause of worldwide infectious diarrhea in healthcare systems (Ananthakrishnan, 2011). Vaccine development has been considered by many to be one way to control the morbidity and relapses due to CDI (Martin and Wilcox, 2016). Most studies on the development of vaccines against CDI focused on the major pathogenic determinants of $C$. difficile, toxin A and B (Martin and Wilcox, 2016). Production of anti-toxin antibodies are considered to be the most effective defense mechanism in mediating systemic and mucosal protection against CDI in both animal models and patients (Pechine and Collignon, 2016). In recent years, numerous studies have reported an increase in the prevalence of TcdA- TcdB + isolates while in vivo evidence demonstrated that such toxigenic strain is fully virulent in hamsters (Alfa et al., 2000; Kuijper et al., 2001; Drudy et al., 2007; Carter et al., 2015).
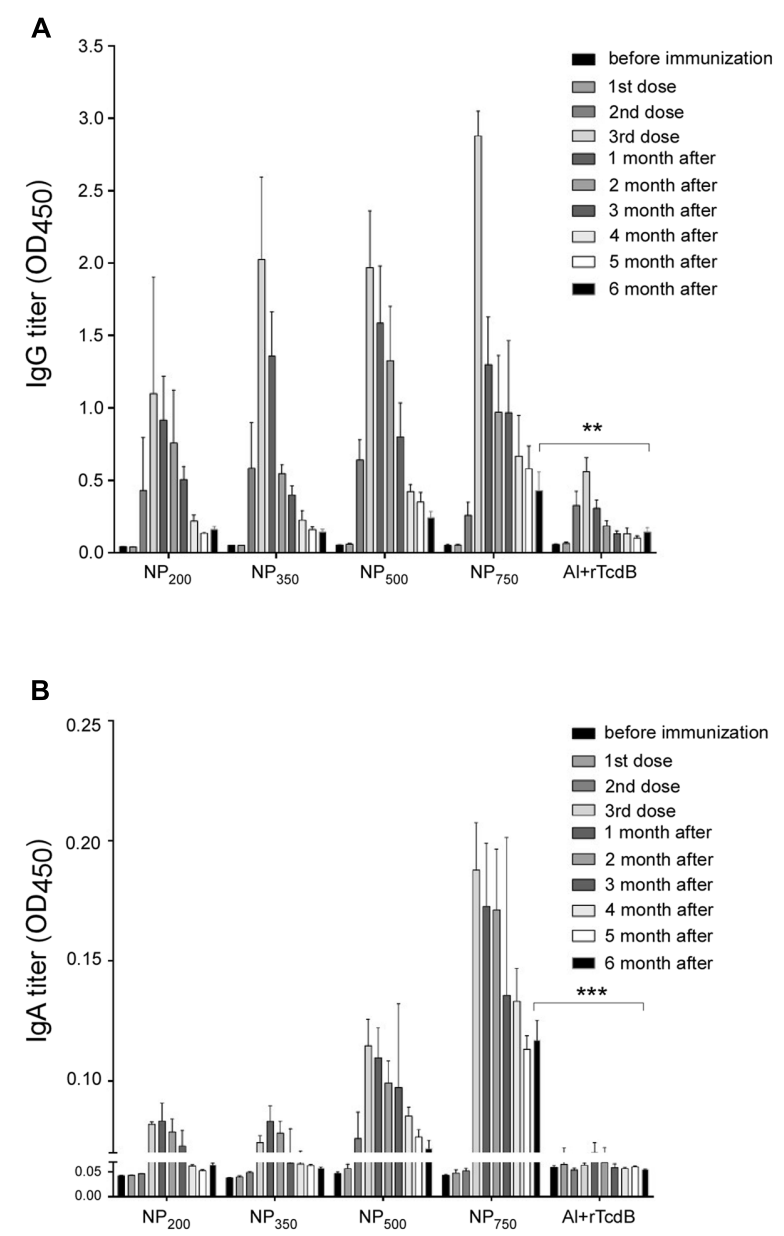

FIGURE 5 | Long-term antibody response of immunized mice. rTcdB-specific $\lg$ (1:20,000 dilution) (A) and IgA (1: 1,000 dilution) (B) titers from the serum of immunized mice were determined by ELISA. NP $200, \mathrm{NP}_{350}, \mathrm{NP}_{500}, \mathrm{NP}_{750}$ : injection with NP-rTcdBs with the corresponding size in nanometers;

Al+rTcdB: injection with $20 \mu \mathrm{g}$ purified $\mathrm{rTcdB}$ mixed with Alum. All data are presented as mean \pm standard deviations and statistical comparisons among groups were analyzed by Student's $t$-test and ANOVA $\left(n=5,{ }^{* *} P \leq 0.01\right.$, $\left.{ }^{* * *} p \leq 0.001,{ }^{* * * *} p \leq 0.0001\right)$. NS, not significant. All data are representative of at least three independent experiments.

Clinically, TcdA-TcdB + isolates have been found to cause the entire symptoms of CDI and in vitro studies have shown TcdB to be more potent than TcdA in causing human colonic tissue necrosis and decreasing barrier function (Hensgens et al., 2012; Eyre et al., 2013; Lim et al., 2014). Studies have shown that the critical antigenic determinants of toxins $\mathrm{B}$ are localized to the repetitive oligopeptides contained within the C-terminal and can induce neutralizing antibody responses (Wang et al., 2012; Baliban et al., 2014; Huang et al., 2015). Equally important in the development of an effective vaccine is adjuvant selection. In this study, we decided to focus on using the receptor domain (residues 1852-2363) of TcdB as a first test of evaluating the potential of using biodegradable nanoparticles as an encapsulating adjuvant.

The polyelectrolyte complex nanoparticles used in this study was formed by the ionic interactions between two oppositely 

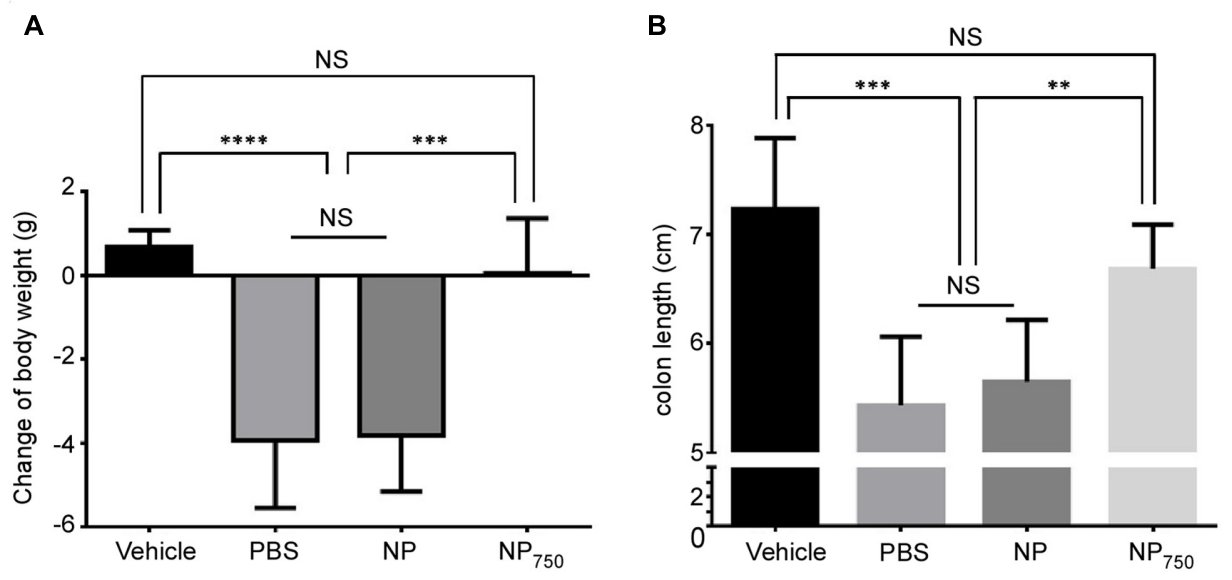

C

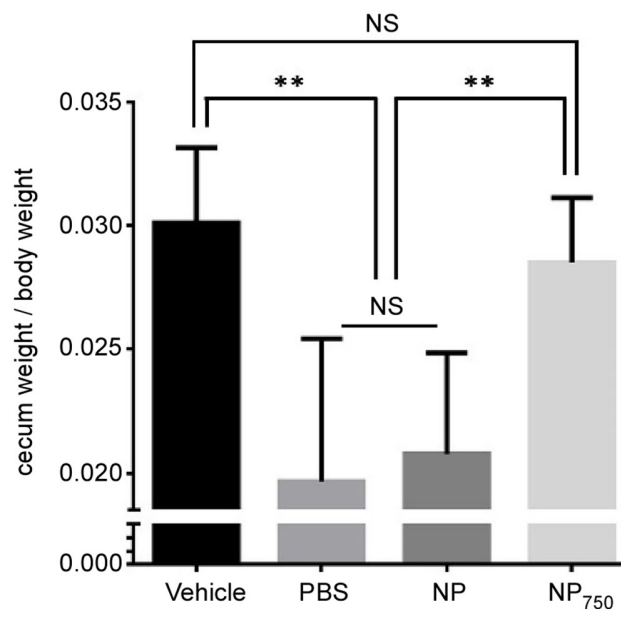

D

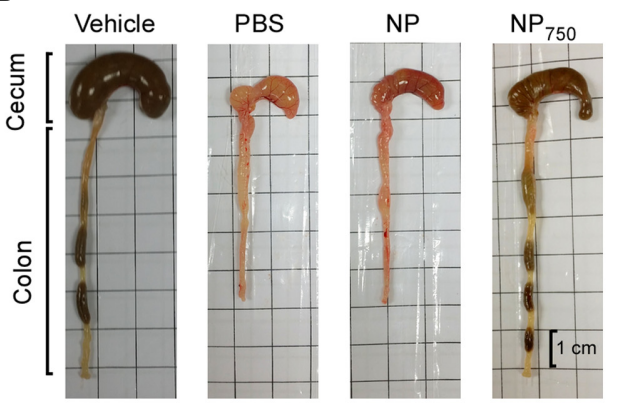

FIGURE 6 | Protection against purified C. difficile spores challenge in vaccinated mice. Various groups of mice were treated with an antibiotic cocktail and then challenged by C. difficile or PBS only for 2 days. Body weight change (A), colon length (B), cecum weight (C), and gross views of cecum and colon (D) were assessed. Vehicle: non-immunized and non-infected group; PBS: mock-immunized and infected group; NP: empty nanoparticle immunized and infected group; $\mathrm{NP}_{750}$ : vaccine immunized and infected group. All data are representative of at least three independent experiments. All data are presented as mean \pm standard deviations and statistical comparisons among groups were analyzed by Student's t-test $\left(* * p \leq 0.01,{ }^{* * *} p \leq 0.001\right)$. NS $=$ not significant.

charged polymers, chitosan (containing positively charged $\mathrm{NH} 3+$ ) and $\gamma$-PGA (containing negatively charged -COO-) (Figure 1D). We were successful in encapsulating the purified rTcdB with these two components to form double-layered nanoparticles with sizes ranging from 200 to $750 \mathrm{~nm}$ in diameter. Surface charge is one of the most important factors affecting the function of nanoparticles in adhering and transporting across the intestinal epithelial cells (Frohlich, 2012; Feng et al., 2015). Positively charged nanoparticles are easier to be taken up by cells than negatively charged ones (Chen L. et al., 2011; Yue et al., 2011). The mechanism by which nanoparticles are transported across the epithelium is still not very well understood. It is probably due to the interaction between the positively charged amino group of the nanoparticles and the negatively charged site on the luminal aspect-oriented epithelial cells. The tight junction protein ZO-1 and F-actin are redistributed which is accompanied by an increase in paracellular permeability and the opening of the tight junction (Ballard et al., 1995; Kotze et al., 1998; Conner and Schmid, 2003; Lin et al., 2007). The other hypothesis of transcellular transport is by nanoparticle absorption (Conner and Schmid, 2003). The hydrophobic nature of nanoparticles helped in creating stronger attachments to anionic cell membrane due to electrostatic interaction, which can result in the transport of the particles across the cells and eventual release at the basolateral pole (Chen M.C. et al., 2011). Moreover, it is known that positively charged nanoparticles can increase CD4+ T-cell activation and germinal center B-cell expansion in the local lymph nodes. Therefore, in the design of our nanoparticle vaccine, the positively charged chitosan was incorporated as the outer layer. Aside from surface charges, 

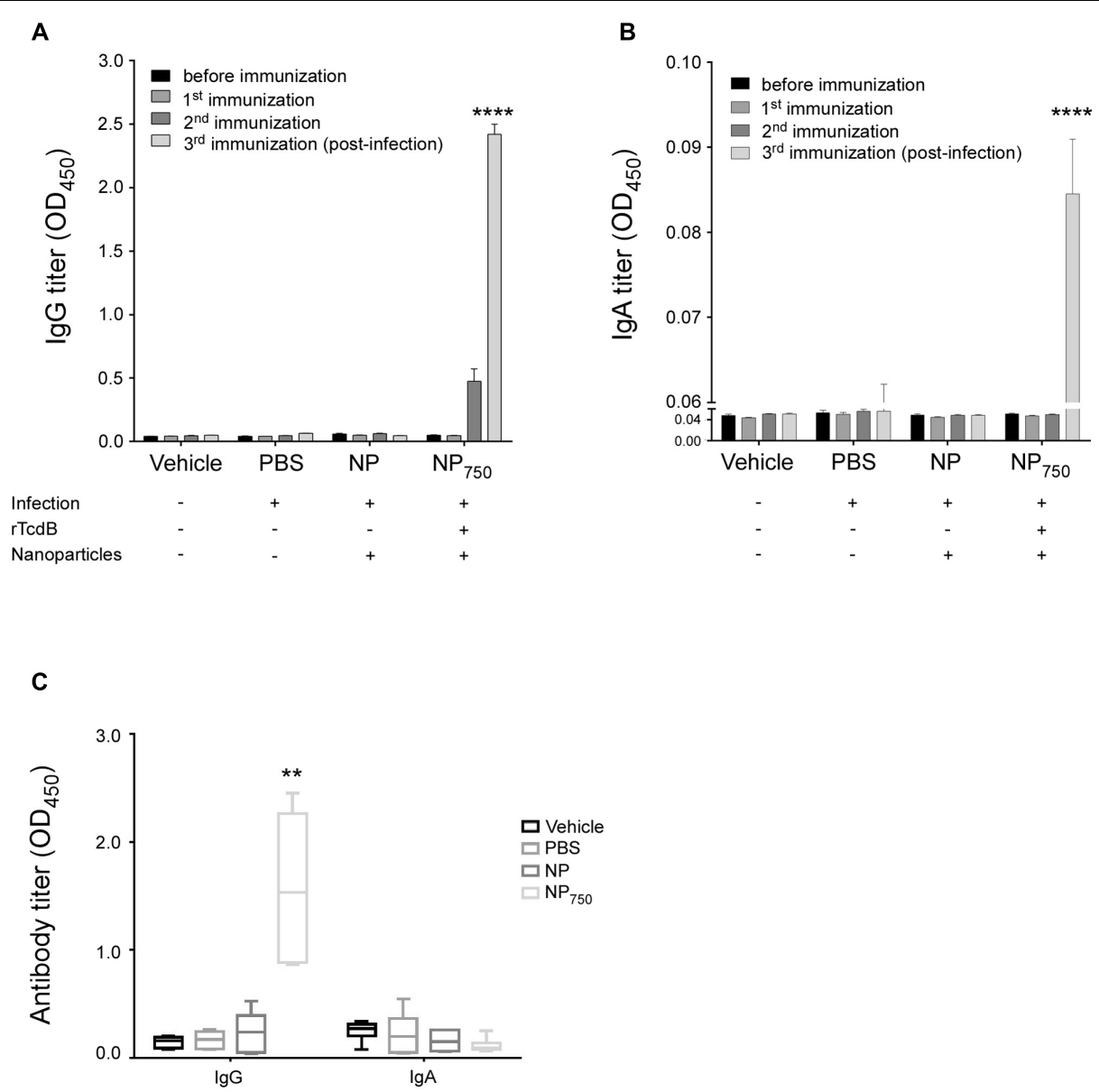

FIGURE 7| Presence of antigen-specific IgG and IgA in NP-rTcdB vaccinated mice after C. difficile challenge. rTcdB-specific lgG (1:20,000 dilution) (A) and IgA (1: 1,000 dilution) (B) from serum of different treatment groups were compared by ELISA. (C) rTcdB-specific IgG and IgA from gastrointestinal lavage (GAL) (1:2 dilution) were also compared. All data are presented as mean \pm standard deviations. Statistical comparisons between NP-rTcdB vaccinated and empty nanoparticle vaccinated group were analyzed by Student's $t$-test $\left.{ }^{* *} P \leq 0.01,{ }^{* * *} p \leq 0.001,{ }^{* * * *} p \leq 0.0001\right)$. All data are representative of at least three independent experiments.

particle size also plays an important role in deciding the cellular localization of polymer particles (Sahoo et al., 2002). Several studies indicated that as particle size decreases, the corresponding antibody responses also diminishes (Giuliano et al., 2002; Gutierro et al., 2002; Katare et al., 2005; Kanchan and Panda, 2007). In our experimental data, the larger NPs indeed elicited higher $\mathrm{rTcdB}$-specific antibody responses, and the highest titer of IgG and IgA were obtained with NPs having a diameter of about $750 \mathrm{~nm}\left(\mathrm{NP}_{750}\right)$. Furthermore, 6 months after the final booster injection, groups that received $\mathrm{NP}_{750}$ retained significantly more IgGs and IgAs compared to other NPS. To induce antibody production using extracellular antigens, it is essential that the peptide fragment of the antigen binds to the MHC II molecule in the plasma membrane of APCs (Trombetta and Mellman, 2005). As particle size decreases, the available surface area of the antigen-loaded particles for attachment may also decrease which can result in lower antibody response. A second possibility to explain our observation is that while virus-sized particles $(20-200 \mathrm{~nm})$ are usually taken up by cells via endocytosis, which results in T-helper type 1 humoral immune response, the larger size NPs (>500 nm) are mainly taken up via phagocytosis and are more likely to promote a T-helper type 2 humoral immune response (Xiang et al., 2006). Additional studies such T lymphocyte proliferation assays are currently underway in our laboratory to characterize in depth the immune responses elicited by the different sized NPs.

The role of the adaptive immunity in the outcome of $C$. difficile colonization and disease progression has been appreciated for many years (Mulligan et al., 1993; Kyne et al., 2000). Initial challenge with $C$. difficile can stimulate IL-10 and IL-4 which in turn stimulate the maturation of naïve $B$ cells and subsequence immunoglobulin production (Ryan et al., 2011). An increase in the level of both toxin-specific IgA and IgG responses have been linked to a decrease in chance of having recurrent CDIs (Kyne et al., 2001). In our study, after three rounds of immunization by i.p. injection higher and longerlasting titers of antigen-specific IgGs were observed when 

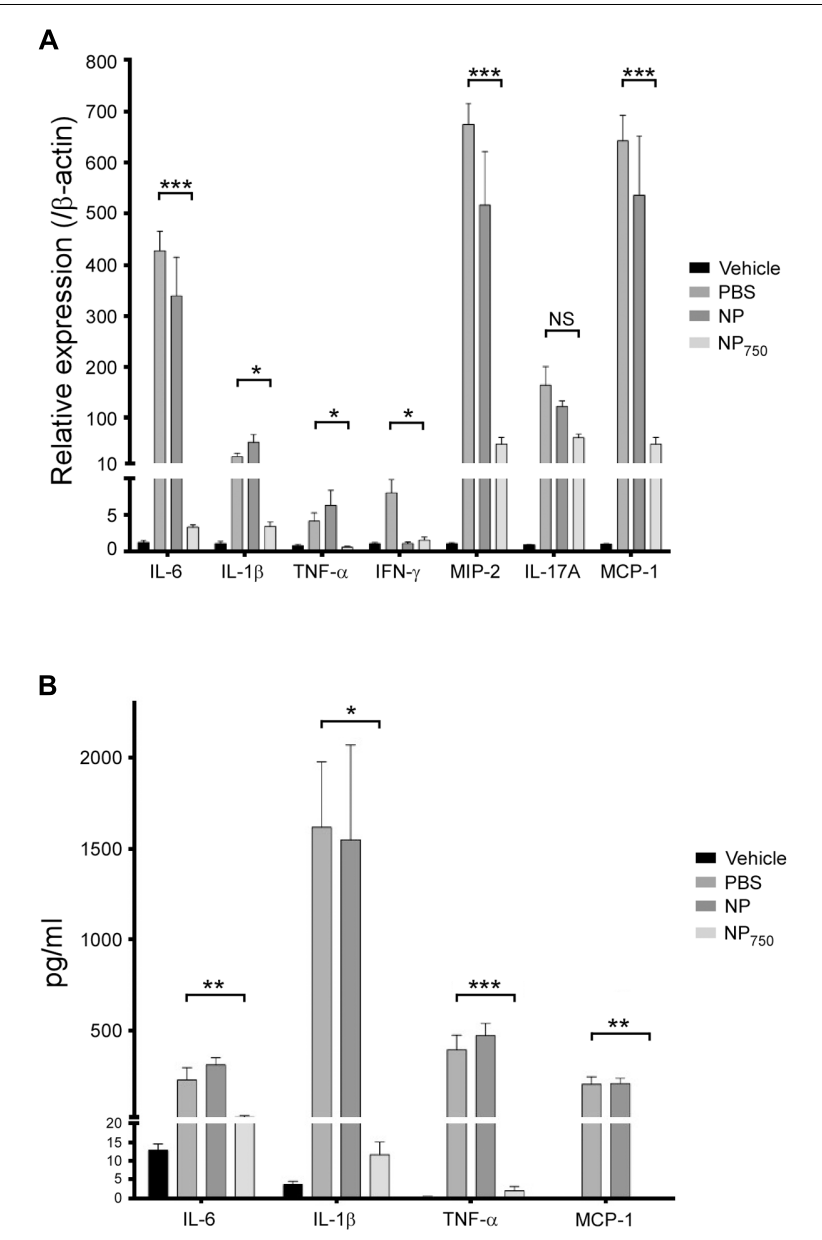

FIGURE 8 | Decreased level of proinflammatory cytokines in C. difficile-infected mice vaccinated by NP-rTcdB. The level of various proinflammatory cytokines and chemokines in colon tissues (A) and GAL (B) of vehicle group, mock-vaccinated group (PBS), empty nanoparticle-vaccinated group, and $\mathrm{NP}_{750}$ vaccinated group as measured by real-time polymerase chain reactions and ELISA, respectively. All data are presented as mean \pm standard deviations and statistical comparisons among groups were analyzed by Student's $t$-test $\left({ }^{*} p \leq 0.05,{ }^{* *} p \leq 0.01\right.$,

$\left.{ }^{* * *} p \leq 0.001,{ }^{* * * *} p \leq 0.0001\right)$. NS, not significant. All data are representative of at least three independent experiments.

mice were given NP-rTcdB as compared to rTcdB premixed with aluminum hydroxide. Likewise, significant IgAs were also detected after NP-rTcdB vaccination. Furthermore, regardless the size of the nanoparticles, the nanoparticle vaccines were able to induce significant antigen-specific IgGs and IgAs, and these antibodies displayed effective toxin B neutralization activity in vitro.

In evaluating the protection afforded by immunization with our nanoparticle vaccine, we observed that immunization with nanoparticle vaccine prior to $C$. difficile infection diminished symptoms of CDI as demonstrated by lower body and cecal weight loss, longer colon, lack of diarrhea, a general healthier cecum and colon morphology, and decrease in the level of colonic and GAL inflammatory cytokine and

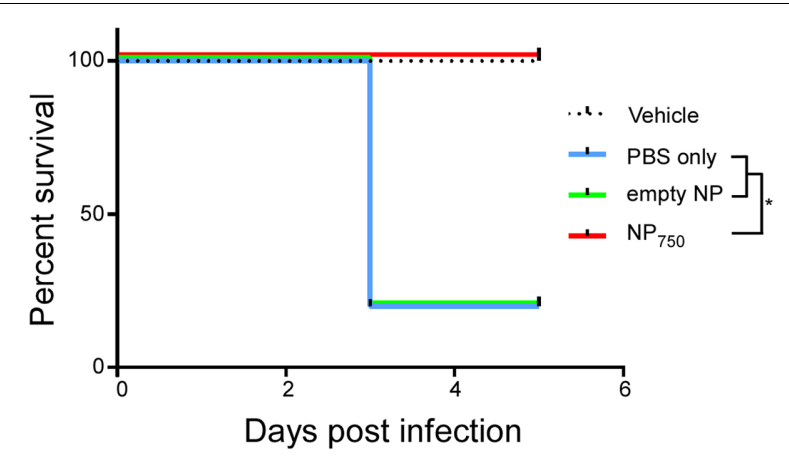

FIGURE 9 | Complete protection against $C$. difficile challenge in vaccinated mice. Various groups of mice were treated with an antibiotic cocktail and then challenged by $C$. difficile or PBS. Survival was monitored for 5 days. Vehicle: health control; PBS: infection control; NP: empty nanoparticle vaccination; $N_{750}$ : NP-rTcdB vaccination. All data are representative of at least three independent experiments $\left({ }^{*} p \leq 0.05\right.$, error bars indicate standard errors of the means; the data were analyzed by Kaplan-Meier survival analysis).

chemokine when compared to mice immunized with PBS or empty nanoparticles. Importantly, immunization with NP100 provided mice $100 \%$ protection from lethal spore challenge as compared to an average of $80 \%$ mortality in mice immunized with PBS or empty nanoparticles. Lastly, we determined the level of rTcdB-specific antibodies in vaccinated mice monthly and observed significant antibody level at 6 months after immunization. Antibody responses of mice vaccinated with nanoparticles were longer lasting than those generated from mice vaccinated with aluminum hydroxide mixed $\mathrm{rTcdB}$ even when the level of the antigen used in the former was five times lesser than used in the latter $(20 \mu \mathrm{g}$ vs. $100 \mu \mathrm{g})$. However, further studies will be required to determine whether these long-lasting antibodies can translate into longer-lasting protection.

The level of serum IgG antibodies against both TcdA and TcdB have been shown to be correlated with protection against CDI (Zhao S. et al., 2014; Kociolek and Gerding, 2016). An early study involving human patients observed correlation between clinical recovery with no relapse with higher TcdB IgG titers. In hospitalized patients, asymptomatic $C$. difficile carriers were found to have significantly higher serum IgG antibody levels compared to those who developed diarrhea (Kyne et al., 2000; Zhao S. et al., 2014). Less is known about the role of serum IgA responses. Johnson et al. (1995) found that serum IgA from patients were able to neutralize the effect of TcdA. The importance of serum IgA against TcdB in resolving CDI remains unclear and will require further investigation. In addition to serum anti-toxin antibody responses, activated DCs will promote a Th2 response which will induce mucosal specific adaptive immunity. Warny et al. (1994) showed that fecal IgA antibody titers were significantly higher in patients who had only single episode of CDI compared to those who relapsed. Similarly, lower level of fecal and colonic IgAs have been shown to correlate with extended diseases and recurrences (Johal et al., 2004; Pechine and Collignon, 2016). In our study, although 
significant induction of mucosal IgGs were observed in colonic lavage fluids for the group that received nanoparticle vaccination, no significant induction of mucosal IgAs were found in colon lavage fluids. We hypothesize this was due to vaccine being delivered intraperitoneally rather than through the mucosal route. The limit of i.p. delivery has also prompted us to begun to evaluate the feasibility of supplying our nanoparticle vaccine via orogastricdelivery. Interestingly, secretory IgAs was detected in colonic lavage fluids and studies are underway to understand whether these antibodies have protective roles (unpublished data).

Since the discovery of $C$. difficile as the major causative agent of antibiotic associated diarrhea, the role of TcdA and TcdB in the underlying disease mechanisms has been well studied. Similarly, numerous vaccine studies have also been initiated. Currently, three vaccines against CDI are being tested in clinical trials (Kociolek and Gerding, 2016). The most advanced being the toxoid vaccine originally developed by Acambis (ACAMCDIFFTM) and now being developed and tested by SanofiPasteur (CDIFFENSE ${ }^{\mathrm{TM}}$ ) (Sougioultzis et al., 2005; Foglia et al., 2012). The intramuscularly delivered vaccine contains formalin inactivated TcdA and TcdB adjuvanted with alum. Both Phase I and Phase II studies have been completed and the vaccine appear to be safe and immunogenic with no adverse events reported. Concerns has been raised for possible residual toxicity associated with formalin inactivation as well as the observation that the vaccine might not be active for weeks to months even after a regimen of three administrations (Zhao S. et al., 2014; Kociolek and Gerding, 2016). A vaccine developed by Pfizer using genetically modified full length TcdA and TcdB have completed phase II testing and phase III begun this year (Tian et al., 2012). VLA84, a recombinant vaccine consisting of truncated TcdA fused to TcdB has completed phase I study (Bezay et al., 2016). Although results from these clinical trials have generally been positive, but the long term protection afforded by these vaccine remains unknown. Since these vaccines targets only toxins, colonization of $C$. difficile in the gastrointestinal tract is not expected to be affected (Kociolek and Gerding, 2016). Similarly, our own study is also limited by using truncated TcdB as the sole antigen, which was shown to have no effect on $C$. difficile colonization. However, the advantages of our strategy in using nanoparticle as vaccine adjuvant are the general safety of the biodegradable material, low production cost, and rapid encapsulation. We have begun to test the

\section{REFERENCES}

Alfa, M. J., Kabani, A., Lyerly, D., Moncrief, S., Neville, L. M., AlBarrak, A., et al. (2000). Characterization of a toxin A-negative, toxin B-positive strain of Clostridium difficile responsible for a nosocomial outbreak of Clostridium difficile-associated diarrhea. J. Clin. Microbiol. 38, 2706-2714.

Ananthakrishnan, A. N. (2011). Clostridium difficile infection: epidemiology, risk factors and management. Nat. Rev. Gastroenterol. Hepatol. 8, 17-26. doi: $10.1038 /$ nrgastro.2010.190

Aslam, S., and Musher, D. M. (2006). An update on diagnosis, treatment, and prevention of Clostridium difficile-associated disease. Gastroenterol. Clin. North Am. 35, 315-335. doi: 10.1016/j.gtc.2006.03.009 effectiveness of encapsulating both toxin fragments as well as surface proteins. Furthermore, the advantage of nanoparticle vaccine is the possibility of inducing mucosal immunity via oral or nasal delivery, which is currently being tested in our lab.

Collectively, results generated from this study suggested that the receptor domain of toxin $B$ encapsulated by a biodegradable chitosan $/ \gamma$-PGA based nanocomplex can elicit strong antigen specific antibody response when given intraperitoneally. Furthermore, such immune response can protect immunized mice from lethal challenge of $C$. difficile spores. Future work will focus on testing the long-term protection potential of the nanoparticle vaccine, and whether protection can be extended to infection by other $C$. difficile clinical isolates. In conclusion, this study demonstrated that nanoparticle-based vaccine may be used as a safe and effective vaccine adjuvant against CDI.

\section{AUTHOR CONTRIBUTIONS}

Y-WL, J-WC, P-JT, and I-HH designed the experiments. Y-WL and Y-HC carried out the experiments, Y-WL, J-WC, and $\mathrm{I}-\mathrm{HH}$ analyzed the data. Y-WL, J-WC, and I-HH prepared the manuscript.

\section{FUNDING}

This work was supported by grant number MOST 102-2320-B006-023-MY3 to I-HH from Ministry of Science and Technology, Taiwan.

\section{ACKNOWLEDGMENTS}

We thank the technical services provided by the members of I-HH lab and laboratory personnel of Y-HC and P-JT.

\section{SUPPLEMENTARY MATERIAL}

The Supplementary Material for this article can be found online at: http://journal.frontiersin.org/article/10.3389/fmicb. 2017.01411/full\#supplementary-material

Awad, M. M., Johanesen, P. A., Carter, G. P., Rose, E., and Lyras, D. (2014). Clostridium difficile virulence factors: insights into an anaerobic spore-forming pathogen. Gut Microbes 5, 579-593. doi: 10.4161/19490976.2014.969632

Baliban, S. M., Michael, A., Shammassian, B., Mudakha, S., Khan, A. S., Cocklin, S., et al. (2014). An optimized, synthetic DNA vaccine encoding the toxin A and toxin $\mathrm{B}$ receptor binding domains of Clostridium difficile induces protective antibody responses in vivo. Infect. Immun. 82, 4080-4091. doi: 10.1128/IAI. 01950- 14

Ballard, S. T., Hunter, J. H., and Taylor, A. E. (1995). Regulation of tight-junction permeability during nutrient absorption across the intestinal epithelium. Annu. Rev. Nutr. 15, 35-55. doi: 10.1146/annurev.nu.15.070195.000343

Bartlett, J. G. (2008). Historical perspectives on studies of Clostridium difficile and C. difficile infection. Clin. Infect. Dis. 46(Suppl. 1), S4-S11. doi: 10.1086/521865 
Bezay, N., Ayad, A., Dubischar, K., Firbas, C., Hochreiter, R., Kiermayr, S., et al. (2016). Safety, immunogenicity and dose response of VLA84, a new vaccine candidate against Clostridium difficile, in healthy volunteers. Vaccine 34, 2585-2592. doi: 10.1016/j.vaccine.2016.03.098

Borgia, G., Maraolo, A. E., Foggia, M., Buonomo, A. R., and Gentile, I. (2015). Fecal microbiota transplantation for Clostridium difficile infection: back to the future. Expert Opin. Biol. Ther. 15, 1001-1014. doi: 10.1517/14712598.2015. 1045872

Braun, V., Hundsberger, T., Leukel, P., Sauerborn, M., and von Eichel-Streiber, C. (1996). Definition of the single integration site of the pathogenicity locus in Clostridium difficile. Gene 181, 29-38.

Carter, G. P., Chakravorty, A., Pham Nguyen, T. A., Mileto, S., Schreiber, F., Li, L., et al. (2015). Defining the roles of TcdA and TcdB in localized gastrointestinal disease, systemic organ damage, and the host response during Clostridium difficile infections. mBio 6:e00551-15. doi: 10.1128/mBio.00551-15

Carter, G. P., Rood, J. I., and Lyras, D. (2012). The role of toxin A and toxin B in the virulence of Clostridium difficile. Trends Microbiol. 20, 21-29. doi: 10.1016/j.tim.2011.11.003

Chen, L., McCrate, J. M., Lee, J. C., and Li, H. (2011). The role of surface charge on the uptake and biocompatibility of hydroxyapatite nanoparticles with osteoblast cells. Nanotechnology 22:105708. doi: 10.1088/0957-4484/22/10/105708

Chen, M. C., Sonaje, K., Chen, K. J., and Sung, H. W. (2011). A review of the prospects for polymeric nanoparticle platforms in oral insulin delivery. Biomaterials 32, 9826-9838. doi: 10.1016/j.biomaterials.2011.08.087

Conner, S. D., and Schmid, S. L. (2003). Regulated portals of entry into the cell. Nature 422, 37-44. doi: 10.1038/nature01451

Di Bella, S., Ascenzi, P., Siarakas, S., Petrosillo, N., and di Masi, A. (2016). Clostridium difficile toxins $\mathrm{A}$ and $\mathrm{B}$ : insights into pathogenic properties and extraintestinal effects. Toxins 8:E134. doi: 10.3390/toxins8050134

Dobson, G., Hickey, C., and Trinder, J. (2003). Clostridium difficile colitis causing toxic megacolon, severe sepsis and multiple organ dysfunction syndrome. Intensive Care Med. 29, 1030. doi: 10.1007/s00134-003-1754-7

Drudy, D., Fanning, S., and Kyne, L. (2007). Toxin A-negative, toxin B-positive Clostridium difficile. Int. J. Infect. Dis. 11, 5-10. doi: 10.1016/j.ijid.2006. 04.003

Eyre, D. W., Cule, M. L., Wilson, D. J., Griffiths, D., Vaughan, A., O'Connor, L., et al. (2013). Diverse sources of C. difficile infection identified on wholegenome sequencing. N. Engl. J. Med. 369, 1195-1205. doi: 10.1056/NEJMoa121 6064

Feng, C., Li, J., Kong, M., Liu, Y., Cheng, X. J., Li, Y., et al. (2015). Surface charge effect on mucoadhesion of chitosan based nanogels for local anti-colorectal cancer drug delivery. Colloids Surf. B Biointerfaces 128, 439-447. doi: 10.1016/j. colsurfb.2015.02.042

Foglia, G., Shah, S., Luxemburger, C., and Pietrobon, P. J. (2012). Clostridium difficile: development of a novel candidate vaccine. Vaccine 30, 4307-4309. doi: $10.1016 /$ j.vaccine.2012.01.056

Frohlich, E. (2012). The role of surface charge in cellular uptake and cytotoxicity of medical nanoparticles. Int. J. Nanomed. 7, 5577-5591. doi: 10.2147/IJN. S36111

Giuliano, E. A., Moore, C. P., and Phillips, T. E. (2002). Morphological evidence of $\mathrm{M}$ cells in healthy canine conjunctiva-associated lymphoid tissue. Graefes Arch. Clin. Exp. Ophthalmol. 240, 220-226. doi: 10.1007/s00417-002-0429-3

Glenny, A. T. (1930). Insoluble precipitates in diphtheria and tetanus immunization. Br. Med. J. 2, 244-245.

Guo, S., Yan, W., McDonough, S. P., Lin, N., Wu, K. J., He, H., et al. (2015). The recombinant Lactococcus lactis oral vaccine induces protection against $C$. difficile spore challenge in a mouse model. Vaccine 33, 1586-1595. doi: 10.1016/j.vaccine.2015.02.006

Gutierro, I., Hernandez, R. M., Igartua, M., Gascon, A. R., and Pedraz, J. L. (2002). Size dependent immune response after subcutaneous, oral and intranasal administration of BSA loaded nanospheres. Vaccine 21, 67-77.

Hensgens, M. P., Keessen, E. C., Squire, M. M., Riley, T. V., Koene, M. G., de Boer, E., et al. (2012). Clostridium difficile infection in the community: a zoonotic disease? Clin. Microbiol. Infect. 18, 635-645. doi: 10.1111/j.1469-0691. 2012.03853.x

Huang, J. H., Wu, C. W., Lien, S. P., Leng, C. H., Hsiao, K. N., Liu, S. J., et al. (2015). Recombinant lipoprotein-based vaccine candidates against $C$. difficile infections. J. Biomed. Sci. 22, 65. doi: 10.1186/s12929-015-0171-x
Hung, Y. P., Ko, W. C., Chou, P. H., Chen, Y. H., Lin, H. J., Liu, Y. H., et al. (2015). Proton-pump inhibitor exposure aggravates Clostridium difficileassociated colitis: evidence from a mouse model. J. Infect. Dis. 212, 654-663. doi: 10.1093/infdis/jiv184

Johal, S. S., Lambert, C. P., Hammond, J., James, P. D., Borriello, S. P., and Mahida, Y. R. (2004). Colonic IgA producing cells and macrophages are reduced in recurrent and non-recurrent Clostridium difficile associated diarrhoea. J. Clin. Pathol. 57, 973-979. doi: 10.1136/jcp.2003.015875

Johnson, S. (2009). Recurrent Clostridium difficile infection: a review of risk factors, treatments, and outcomes. J. Infect. 58, 403-410. doi: 10.1016/j.jinf.2009.03.010

Johnson, S., Sambol, S. P., Brazier, J. S., Delmee, M., Avesani, V., Merrigan, M. M., et al. (2003). International typing study of toxin A-negative, toxin B-positive Clostridium difficile variants. J. Clin. Microbiol. 41, 1543-1547.

Johnson, S., Sypura, W. D., Gerding, D. N., Ewing, S. L., and Janoff, E. N. (1995). Selective neutralization of a bacterial enterotoxin by serum immunoglobulin A in response to mucosal disease. Infect. Immun. 63, 3166-3173.

Kalam, M. A., Khan, A. A., and Alshamsan, A. (2017). Non-invasive administration of biodegradable nano-carrier vaccines. Am. J. Transl. Res. 9, 15-35.

Kanchan, V., and Panda, A. K. (2007). Interactions of antigen-loaded polylactide particles with macrophages and their correlation with the immune response. Biomaterials 28, 5344-5357. doi: 10.1016/j.biomaterials.2007.08.015

Karch, C. P., and Burkhard, P. (2016). Vaccine technologies: from whole organisms to rationally designed protein assemblies. Biochem. Pharmacol. 120, 1-14. doi: 10.1016/j.bcp.2016.05.001

Katare, Y. K., Muthukumaran, T., and Panda, A. K. (2005). Influence of particle size, antigen load, dose and additional adjuvant on the immune response from antigen loaded PLA microparticles. Int. J. Pharm. 301, 149-160. doi: 10.1016/j. ijpharm.2005.05.028

Kociolek, L. K., and Gerding, D. N. (2016). Breakthroughs in the treatment and prevention of Clostridium difficile infection. Nat. Rev. Gastroenterol. Hepatol. 13, 150-160. doi: 10.1038/nrgastro.2015.220

Kotze, A. F., Luessen, H. L., de Leeuw, B. J., de Boer, A. G., Verhoef, J. C., and Junginger, H. E. (1998). Comparison of the effect of different chitosan salts and N-trimethyl chitosan chloride on the permeability of intestinal epithelial cells (Caco-2). J. Control. Release 51, 35-46.

Kuehne, S. A., Cartman, S. T., Heap, J. T., Kelly, M. L., Cockayne, A., and Minton, N. P. (2010). The role of toxin A and toxin B in Clostridium difficile infection. Nature 467, 711-713. doi: 10.1038/nature09397

Kuijper, E. J., de Weerdt, J., Kato, H., Kato, N., van Dam, A. P., van der Vorm, E. R., et al. (2001). Nosocomial outbreak of Clostridium difficile-associated diarrhoea due to a clindamycin-resistant enterotoxin A-negative strain. Eur. J. Clin. Microbiol. Infect. Dis. 20, 528-534.

Kyne, L., Warny, M., Qamar, A., and Kelly, C. P. (2000). Asymptomatic carriage of Clostridium difficile and serum levels of IgG antibody against toxin A. N. Engl. J. Med. 342, 390-397. doi: 10.1056/NEJM200002103420604

Kyne, L., Warny, M., Qamar, A., and Kelly, C. P. (2001). Association between antibody response to toxin $\mathrm{A}$ and protection against recurrent Clostridium difficile diarrhoea. Lancet 357, 189-193. doi: 10.1016/S0140-6736(00)03592-3

Leroux-Roels, G. (2010). Unmet needs in modern vaccinology: adjuvants to improve the immune response. Vaccine 28(Suppl. 3), C25-C36. doi: 10.1016/ j.vaccine.2010.07.021

Lim, S. K., Stuart, R. L., Mackin, K. E., Carter, G. P., Kotsanas, D., Francis, M. J., et al. (2014). Emergence of a ribotype 244 strain of Clostridium difficile associated with severe disease and related to the epidemic ribotype 027 strain. Clin. Infect. Dis. 58, 1723-1730. doi: 10.1093/cid/ciu203

Lin, Y. H., Mi, F. L., Chen, C. T., Chang, W. C., Peng, S. F., Liang, H. F., et al. (2007). Preparation and characterization of nanoparticles shelled with chitosan for oral insulin delivery. Biomacromolecules 8, 146-152. doi: 10.1021/bm060 7776

Lin, Y.-S., and Chen, Y.-H. (2017). Biodegradable nanocomplex. U.S. Patent No 20170043007. Washington, DC: U.S. Patent and Trademark Office.

Martin, J., and Wilcox, M. (2016). New and emerging therapies for Clostridium difficile infection. Curr. Opin. Infect. Dis. 29, 546-554. doi: 10.1097/QCO. 0000000000000320

Maynard-Smith, M., Ahern, H., McGlashan, J., Nugent, P., Ling, R., Denton, H., et al. (2014). Recombinant antigens based on toxins A and B of Clostridium difficile that evoke a potent toxin-neutralising immune response. Vaccine 32, 700-705. doi: 10.1016/j.vaccine.2013.11.099 
Mishra, N., Goyal, A. K., Tiwari, S., Paliwal, R., Paliwal, S. R., Vaidya, B., et al. (2010). Recent advances in mucosal delivery of vaccines: role of mucoadhesive/biodegradable polymeric carriers. Expert Opin. Ther. Pat. 20, 661-679. doi: 10.1517/13543771003730425

Monot, M., Eckert, C., Lemire, A., Hamiot, A., Dubois, T., Tessier, C., et al. (2015). Clostridium difficile: new insights into the evolution of the pathogenicity locus. Sci. Rep. 5:15023. doi: 10.1038/srep15023

Moon, H. J., Lee, J. S., Talactac, M. R., Chowdhury, M. Y., Kim, J. H., Park, M. E., et al. (2012). Mucosal immunization with recombinant influenza hemagglutinin protein and poly gamma-glutamate/chitosan nanoparticles induces protection against highly pathogenic influenza A virus. Vet. Microbiol. 160, 277-289. doi: 10.1016/j.vetmic.2012.05.035

Mulligan, M. E., Miller, S. D., McFarland, L. V., Fung, H. C., and Kwok, R. Y. (1993). Elevated levels of serum immunoglobulins in asymptomatic carriers of Clostridium difficile. Clin. Infect. Dis. 16(Suppl. 4), S239-S244.

Pechine, S., and Collignon, A. (2016). Immune responses induced by Clostridium difficile. Anaerobe 41, 68-78. doi: 10.1016/j.anaerobe.2016.04.014

Reddy, S. T., van der Vlies, A. J., Simeoni, E., Angeli, V., Randolph, G. J., O’Neil, C. P., et al. (2007). Exploiting lymphatic transport and complement activation in nanoparticle vaccines. Nat. Biotechnol. 25, 1159-1164. doi: 10.1038/nbt1332

Ryan, A., Lynch, M., Smith, S. M., Amu, S., Nel, H. J., McCoy, C. E., et al. (2011). A role for TLR4 in Clostridium difficile infection and the recognition of surface layer proteins. PLoS Pathog. 7:e1002076. doi: 10.1371/journal.ppat.1002076

Sahoo, S. K., Panyam, J., Prabha, S., and Labhasetwar, V. (2002). Residual polyvinyl alcohol associated with poly (D,L-lactide-co-glycolide) nanoparticles affects their physical properties and cellular uptake. J. Control. Release 82, 105-114.

Sorg, J. A., and Sonenshein, A. L. (2008). Bile salts and glycine as cogerminants for Clostridium difficile spores. J. Bacteriol. 190, 2505-2512. doi: 10.1128/JB. 01765-07

Sougioultzis, S., Kyne, L., Drudy, D., Keates, S., Maroo, S., Pothoulakis, C., et al. (2005). Clostridium difficile toxoid vaccine in recurrent C. difficile-associated diarrhea. Gastroenterology 128, 764-770.

Spencer, J., Leuzzi, R., Buckley, A., Irvine, J., Candlish, D., Scarselli, M., et al. (2014). Vaccination against Clostridium difficile using toxin fragments: observations and analysis in animal models. Gut Microbes 5, 225-232. doi: 10.4161/gmic. 27712

Tian, J. H., Fuhrmann, S. R., Kluepfel-Stahl, S., Carman, R. J., Ellingsworth, L., and Flyer, D. C. (2012). A novel fusion protein containing the receptor binding domains of $C$. difficile toxin $A$ and toxin B elicits protective immunity against lethal toxin and spore challenge in preclinical efficacy models. Vaccine 30, 4249-4258. doi: 10.1016/j.vaccine.2012.04.045
Trombetta, E. S., and Mellman, I. (2005). Cell biology of antigen processing in vitro and in vivo. Annu. Rev. Immunol. 23, 975-1028. doi: 10.1146/annurev. immunol.22.012703.104538

Wang, H., Sun, X., Zhang, Y., Li, S., Chen, K., Shi, L., et al. (2012). A chimeric toxin vaccine protects against primary and recurrent Clostridium difficile infection. Infect. Immun. 80, 2678-2688. doi: 10.1128/IAI.00215-12

Wang, Y. K., Yan, Y. X., Kim, H. B., Ju, X., Zhao, S., Zhang, K., et al. (2015). A chimeric protein comprising the glucosyltransferase and cysteine proteinase domains of toxin $\mathrm{B}$ and the receptor binding domain of toxin $\mathrm{A}$ induces protective immunity against Clostridium difficile infection in mice and hamsters. Hum. Vaccin. Immunother. 11, 2215-2222. doi: 10.1080/21645515. 2015.1052352

Warny, M., Vaerman, J. P., Avesani, V., and Delmee, M. (1994). Human antibody response to Clostridium difficile toxin $\mathrm{A}$ in relation to clinical course of infection. Infect. Immun. 62, 384-389.

Xiang, S. D., Scholzen, A., Minigo, G., David, C., Apostolopoulos, V., Mottram, P. L., et al. (2006). Pathogen recognition and development of particulate vaccines: does size matter? Methods 40, 1-9. doi: 10.1016/j.ymeth.2006. 05.016

Yue, Z. G., Wei, W., Lv, P. P., Yue, H., Wang, L. Y., Su, Z. G., et al. (2011). Surface charge affects cellular uptake and intracellular trafficking of chitosan-based nanoparticles. Biomacromolecules 12, 2440-2446. doi: 10.1021/bm101482r

Zhao, K., Zhang, Y., Zhang, X., Shi, C., Wang, X., Wang, X., et al. (2014). Chitosancoated poly(lactic-co-glycolic) acid nanoparticles as an efficient delivery system for Newcastle disease virus DNA vaccine. Int. J. Nanomed. 9, 4609-4619. doi: 10.2147/IJN.S70633

Zhao, S., Ghose-Paul, C., Zhang, K., Tzipori, S., and Sun, X. (2014). Immunebased treatment and prevention of Clostridium difficile infection. Hum. Vaccin. Immunother. 10, 3522-3530. doi: 10.4161/21645515.2014.980193

Conflict of Interest Statement: The authors declare that the research was conducted in the absence of any commercial or financial relationships that could be construed as a potential conflict of interest.

Copyright (c) 2017 Liu, Chen, Chen, Tsai and Huang. This is an open-access article distributed under the terms of the Creative Commons Attribution License (CC BY). The use, distribution or reproduction in other forums is permitted, provided the original author(s) or licensor are credited and that the original publication in this journal is cited, in accordance with accepted academic practice. No use, distribution or reproduction is permitted which does not comply with these terms. 